\title{
Depression among smokers of a web-based intervention to quit smoking: a cross-sectional study
}

\author{
Henrique Pinto Gomide, ${ }^{1,2}$ Cristiana Rodrigues Teixeira de Carvalho, ${ }^{1}$ Miriane Lovisi Menezes, ${ }^{1}$ Isadora Gazolla \\ de Oliveira, ${ }^{1}$ Renata Giovannini Furtado de Mendonça, ${ }^{1}$ Roberto Duque de Albuquerque Júnior, ${ }^{1}$ Nathália Munck \\ Machado, ${ }^{2}$ Rafaela Russi Ervilha, ${ }^{2}$ Thiago Costa Rizuti da Rocha, ${ }^{2}$ Heder Soares Bernardino, ${ }^{2}$ Telmo Mota Ronzani ${ }^{2}$
}

\footnotetext{
1 Centro de Ensino Superior de Juiz de Fora, Juiz de Fora, Brazil.

2 Universidade Federal de Juiz de Fora, Juiz de Fora, Minas Gerais, Brazil.

Correspondence:

Henrique Pinto Gomide

Centro de Ensino Superior de Juiz de Fora.

R. Halfeld, 1179, Centro, Juiz de Fora, Minas Gerais, Brazil, CEP: 36016-000.

Email: henriquepgomide@gmail.com
}

Received first version: June 8, 2017 Second version: September 27, 2017

Accepted: November 10, 2017

doi:10.17711/SM.0185-3325.2017.035

\begin{abstract}
Introduction. Web-based interventions for smoking cessation are an innovative strategy to reduce the burden of smoking. Although many web-based interventions are freely available in many languages and have proven to be effective, so far no study has covered in detail the association between depression and smoking. Objective. The aim of this study was to evaluate the prevalence of depression among users of the Viva sem Tabaco, a web-based intervention for smoking cessation. Method. This was a retrospective cross-sectional study. In the internet-based intervention participated 1433. Inclusion criteria were: being 18 years or older and a smoker; exclusion criteria were: omitting to fill out two questions of the screening depression questionnaire PHQ-2 and having made multiple accesses within a limited time span, characterizing invalid access. At the end, the sample had 461 participants. Participants answered questions related to sociodemographic characteristics, tobacco history, depression (PHQ-2 and PHQ-9), alcohol use, and intervention use. Results. Participants average age was 42.3 years $(S D=12.1)$. Most participants were female $(67 \%)$, and $70 \%$ were employed during the time of the study. From the total sample, $36.4 \%$ of the participants presented depression according to $\mathrm{PHQ}-2$. Being screened with depression was associated with tobacco dependence $(\mathrm{OR}=1.10$; $95 \% \mathrm{Cl}=1.00,1.20)$, and associated with not having a job $(\mathrm{OR}=.53 ; 95 \% \mathrm{Cl}=.29, .97)$. Discussion and conclusion. Depression may be a factor to be considered in programs that offer support to quit smoking through the internet for Portuguese Speakers.
\end{abstract}

Keywords: Smoking cessation, depression, tobacco use cessation, tobacco use cessation products, internet.

\section{RESUMEN}

Introducción. Las intervenciones en línea para la interrupción del tabaquismo son una estrategia innovadora para reducir el nivel de consumo de tabaco. Aunque hay muchas intervenciones en línea gratuitas en varios idiomas que han demostrado ser eficaces, ningún estudio ha abarcado detalladamente la asociación entre depresión y tabaquismo. Objetivo. El objetivo de este estudio fue evaluar la prevalencia de depresión entre usuarios de una intervención en línea para dejar de fumar. Método. Se trata de un estudio transversal retrospectivo. 1433 participantes fueron invitados para participar de la intervención mediada por internet. Los criterios de inclusión fueron tener 18 años o más y ser fumador; los criterios de exclusión fueron no haber marcado dos preguntas del cuestionario de detección de depresión PHQ-2 y haber realizado múltiples accesos dentro de un lapso de tiempo limitado, lo que se caracterizó como un acceso no válido. Los participantes $(N=461)$ respondieron a preguntas relacionadas con características sociodemográficas, historia del tabaco, depresión (PHQ-2 y PHQ-9), uso de alcohol y uso de la intervención. Resultados. De la muestra total, el $36.4 \%$ de los participantes presentaron depresión de acuerdo con el PHQ-2. La depresión se asoció con la dependencia del tabaco $(O R=1.10 ; 95 \% \mathrm{IC}=1.00,1.20)$ y asociada con no tener un empleo $(\mathrm{OR}=.53 ; 95 \% \mathrm{IC}=.29, .97)$. Discusión y conclusión. La depresión es un factor que se debe considerar en los programas que ofrecen apoyo para dejar de fumar a través de Internet para hablantes de portugués.

Palabras clave: Cese del tabaquismo, depresión, cese del uso de tabaco, productos para dejar de fumar tabaco, internet. 


\section{INTRODUCTION}

Smoking is the leading cause of preventable death. According to the World Health Organization (WHO), 1.2 billion people smoke and nearly $80 \%$ of those live in developing countries (WHO, 2008). Smokers have more comorbidities than non-smokers (Farrell et al., 2001; Hitsman, Borrelli, McChargue, Spring, \& Niaura, 2003; McClave et al., 2009). Smokers are 1.6 times more likely to have a psychiatric disorder as depression, phobia, and generalized anxiety disorder. The association between smoking and depression has been subject of numerous studies (Covey, Glassman, \& Stetner, 1990; Hitsman et al., 2003; Husky, Mazure, Paliwal, \& McKee, 2008; Kendler et al., 1993; McClave et al., 2009). Depressed smokers have higher levels of nicotine dependence and they are more likely to relapse and less inclined to quit smoking (Reid \& Ledgerwood, 2016; Zvolensky, Bakhshaie, Sheffer, Perez, \& Goodwin, 2015). Nonetheless, depressed smokers are also less motivated to quit (Morozova, Rabin, \& George, 2015).

Many approaches are proven to be effective for smoking cessation (Hartmann-Boyce, Stead, Cahill, \& Lancaster, 2013). Web-based and m-health interventions are considered innovative and attractive by young smokers and women who smoke. These interventions may benefit smokers who are willing to quit when used alongside with other treatments, such as nicotine replacement therapy and counseling (Civljak, Stead, Hartmann-Boyce, Sheikh, \& Car, 2013). Web-based and m-health interventions can be used in the absence of any other treatment, in relapse prevention, and as a complement to standard care. Moreover, they can be accessed simultaneously and are available in multiple languages (Muñoz, 2010).

There is debate an ongoing as to which treatments are best suited for depressed smokers. It is known, however, that smoking cessation treatment does not exacerbate depression symptoms. Whereas relapse is associated with depressive symptoms, depression does not have a negative impact on cessation outcomes, and the self-medication hypothesis (i.e., individuals take substances of abuse to ameliorate symptoms) does not account for tobacco dependence and depression comorbidity (van der Meer, Willemsen, Smit, \& Cuijpers, 2013). In addition, studies suggest that cessation rates increase in smokers with current and past depression when psychosocial mood management is combined to standard treatment (van der Meer et al., 2013). According to Taylor et al. (2014), quitting smoking is associated with lower levels of anxiety and stress, and better quality of life.

In regard to web-based and m-health interventions, little attention has been given to depression and other comorbidities (Civljak et al., 2013). Only few studies assessed depression, and they found that $12-40 \%$ of the participants met criteria for depression (Bricker, Wyszynski, Comstock,
\& Heffner, 2013; Muñoz et al., 2009; Rabius, Pike, Wiatrek, $\&$ McAlister, 2008). The aim of this study is to evaluate the prevalence of depressive symptoms among users of an open-source web-based intervention for smoking cessation and also the participants' characteristics associated with depression.

\section{METHOD}

\section{Design}

This was a cross-sectional study.

\section{Subjects}

All 1433 users who had signed up for a web-based intervention for smoking cessation were invited to enroll between October 2013 and March 2017. Inclusion criteria were being 18 years or older, smoker, and in agreement with the consent term. Participants who did not answer the questions of screening depression and test accounts were excluded. After these procedures, data from 461 (32.2\%) participants were analyzed.

\section{Measures}

All measures included were chosen after a bibliographic review on smoking cessation studies, including randomized clinical trials of internet interventions (Bricker et al., 2013; Muñoz et al., 2009; Rabius et al., 2008).

Sample characteristics and smoking history. We measured age, gender, education, and employment (Are you employed?). Smoking history was measured by such as questions the number of cigarettes smoked per day (How many cigarettes per day do you smoke?) and the number of previous quitting attempts (How many times have you tried to quit smoking?). Questions were adapted from the Global Adult Tobacco Survey (2010).

Patient Health Questionnaire (PHQ-2 and PHQ-9). We used the PHQ-2 to screen depression and the PHQ-9 (Manea, Gilbody, \& McMillan, 2015; Pettersson, Boström, Gustavsson, \& Ekselius, 2015) to evaluate the severity of depression and the existence of a major depressive disorder. PHQ-2 is a two-item questionnaire, where each item is scored $0-3$, with questions that address depressive humor and anhedonia in the past two weeks ("Little interest or pleasure in doing things" and "Feeling down, depressed, or hopeless"). As all participants were Brazilians, we used the cut-point proposed by Santos et al. (2013). PHQ-9 is a nineitem questionnaire, each item scored $0-3$. The severity score of PHQ-9 is calculated by summing the scores of each question. PHQ-9 scores range from 0 to 27, scores of 5, 10, 15, and 20 represent cut points for mild, moderate, moderately 
severe, and severe depression, respectively. Both versions have been validated in several samples as pointed out by Manea et al. (2015), including Brazilian samples (Santos et al., 2013).

Contemplation ladder. It is a single question scale that assesses the readiness to change. Smokers choose one of ten options that better describes their readiness to quit. Scores range from 0 to 10 , where 0 means not motivated at all ("I like smoking and I do not consider quitting") and 10 totally motivated ("I have already quit and I am not going to smoke again"). The scale is validated and used in a Brazilian quitline service (Terra et al., 2009).

Fagerström Test of Nicotine Dependence (FTND). FTND assesses nicotine dependence (Heatherton, Kozlowski, Frecker, \& Fagerström, 1991). This is a six-item questionnaire widely recommended in clinical guidelines (US Department of Health and Human Services, 2008) and also research studies. Scores range from 0 to 10; scores of 2, 4, 5, 7, 10 represents cut-points of very low, low, moderate, high, and very high nicotine dependence, respectively. The scale is validated in Brazilian samples (De Meneses-Gaya et al., 2009).

Alcohol Use Disorders Identification Test Consumption (AUDIT-C). AUDIT-C screens alcohol use disorders or hazardous drinking and was developed by the World Health Organization. It is a three-item questionnaire, scored in a scale of $0-12$, where values higher than 4 in men or 3 in women are considered positive. Generally, higher scores mean higher odds that alcohol is affecting user's health and safety. The test is validated in Brazil (De Meneses-Gaya et al., 2010).

\section{Procedures}

Participants were recruited from different sources: social media (Facebook Ads), Google Ads, email, and news published on the internet. Recruitment strategies were primarily aimed to enroll new users in the web-based intervention "Viva sem Tabaco". "Viva sem Tabaco" is an open-source web-based intervention for smoking cessation, available in seven languages (Portuguese, Spanish, English, Russian, Arabic, Italian, and German); it is fully automated, and its content is based on guidelines for treating smokers (US Department of Health Services, 2008) and meta-analyses published by the "Cochrane Tobacco Addiction Group" (Cahill, Lancaster, \& Green, 2010; Civljak et al., 2013; Hartmann-Boyce et al., 2013). The intervention content is structured in three major areas according to the user degree of motivation for change. More details on intervention development can be found in Gomide, Bernardino, Richter, Martins, and Ronzani (2016).

Users were invited to enroll in the study after they filled the registration form. The consent form and the site policy were provided to the participants by means of links.
The consent form was sent by e-mail to those who agreed to participate in the study. After consent, participants answered the following questionnaires: characterization of the subjects and smoking history, Patient Health Questionnaire (PHQ-2), Fagerstrom Test for Nicotine Dependence (FTND), Contemplation Ladder, and AUDIT-C. After that, participants could navigate the intervention content. Additionally, 345 (74.8\%) out of 461 users filled the Patient Health Questionnaire (PHQ-9), available in one intervention page intervention about smoking and depression. Data collection with missing cases is depicted in Figure 1. The depression page suggests users that meet criteria for depression to seek professional help to quit smoking and acknowledges that depression reduces the odds of quitting.

\section{Statistical analysis}

Data were collected from the intervention database. Tables from the database were merged using a primary key. To remove possible false user accounts (i. e., excessive clicks on the same page; access to multiple pages in a short timespan), we inspected all cases. After that, we compared the intervention usage (time spent on the intervention and average number of pages accessed) among those who filled in all questionnaires and those who did not in order to check if data missingness was not at random, one of the assumptions of the multiple imputation method. No significant differences were found. Then, we conducted exploratory analysis and applied test $\chi^{2}$, t-test and Spearman's correlation. To identify characteristics related to positive screening for depression (PHQ-2 > 2), we performed logistic regression analysis. First, we added variables found to be related to depression: nicotine dependence and employment. Then, we added the variables: gender, age, education, motivation to

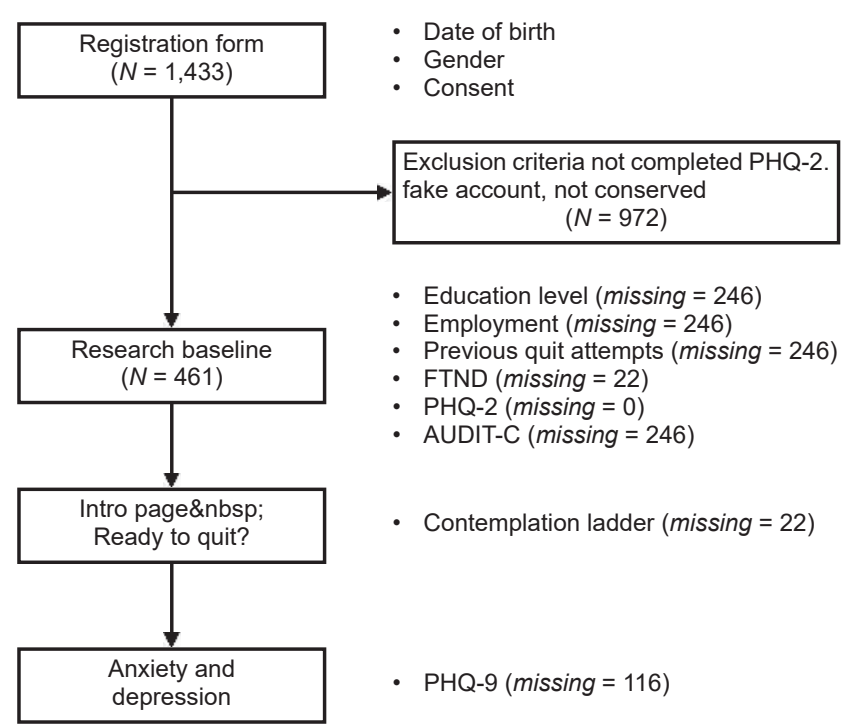

Figure 1. Data collection by intervention page and missing cases. 
quit, nicotine dependence, cigarettes smoked per day, audit score, previous quit attempts, and number of pages visited. The percentage of missing across the variables ranged between 0 and $53 \%$. The main reason of missing values was the inclusion of a questionnaire after the sign-in form, part of an update. We used multiple imputation (Rubin, 1987) to create and analyze 55 multiply imputed datasets. Data analysis was performed using R (v.3.2) (R Core Team, 2017) and the following packages mlogit (Croissant, 2013) and mice (v.2.2) (Buuren \& Groothuis-Oudshoorn, 2011). Model parameters were estimated with multiple regression applied to each imputed dataset separately. These estimates and their standard errors were combined using Rubin's rules (1987). For comparison, we performed the analyses on the subset of complete cases. We adopted $p<.05$ as the criteria for statistical significance.

\section{Ethical considerations}

All research procedures were performed after approval of the Institutional Review Board of the Universidade Federal de Juiz de Fora (n. CEP - 1376638). Users who received a positive screen for depression were prompted to the following message: "Your score suggests that you have significant depressive symptoms. We recommend seeing a doctor to help you in trying to quit smoking. Remember that the use of medication and psychotherapy increase your chances of success! However, feel free to go to the next step".

\section{RESULTS}

\section{Sample characteristics}

Most participants were female (67\%), with a mean age of 42.3 years $(\mathrm{SD}=12.1)$. The majority of the sample had a high school as higher scholarly (55.9\%), 24.7\% higher education, $11.8 \%$ elementary school and $7.5 \%$ postgraduate. Seventy one percent were employed at the time of the study. Ninety-three percent of participants said they tried to quit smoking. Among those who tried to quit smoking, the median number of attempts was 3.5 (IQR = 4). Approximately one-third of the participants $(36.4 \%)$ presented symptoms indicative of depression according to the PHQ-2 criteria. The characteristics of the participants are described in Table 1.

Among users who completed all PHQ-9 questions, $(N=461), 38.3 \%$ were diagnosed with major depression syndrome. The classification of severity according to PHQ9 is described in Figure 1. There was a low correlation between the PHQ-9 score and the Fagerstrom Nicotine Dependence Test score $(r=.2 ; t(4), g l=300, p<.001)$, as shown in Table 2.

\section{Logistic regression}

Regression models are depicted in Table 3. Level of nicotine dependence and employment status were considered signif-

Table 1

Comparison between sociodemographic measures, smoking history, motivation to quit, alcohol drinking, and intervention usage by participants with respect to an algorithm for depression detection using the instrument PHQ-2 ( $\mathrm{n}=461)$

\begin{tabular}{|c|c|c|c|}
\hline \multirow[b]{2}{*}{ Variables } & \multicolumn{3}{|c|}{ Depression screening (PHQ-2 > 2) } \\
\hline & Yes & No & $p$-value \\
\hline Age (Mean, SD) & $42.11(11.92)$ & $42.31(12.17)$ & .87 \\
\hline Gender (\%) & & & .26 \\
\hline $\begin{array}{l}\text { Female } \\
\text { Male }\end{array}$ & $\begin{array}{l}70.2 \\
29.7\end{array}$ & $\begin{array}{l}65.1 \\
34.9\end{array}$ & \\
\hline Education (\%) & & & .60 \\
\hline $\begin{array}{l}\text { Elementary } \\
\text { High School } \\
\text { College } \\
\text { Graduation }\end{array}$ & $\begin{array}{r}17.3 \\
50.7 \\
24.0 \\
8.0\end{array}$ & $\begin{array}{r}12.9 \\
59.7 \\
19.4 \\
7.9\end{array}$ & \\
\hline Working (\%) & & & $.03^{*}$ \\
\hline $\begin{array}{l}\text { Yes } \\
\text { No }\end{array}$ & $\begin{array}{l}45.3 \\
54.7\end{array}$ & $\begin{array}{l}69.1 \\
30.9\end{array}$ & \\
\hline PHQ-9 Score (Average, SD) & $15.8(5.6)$ & $6.3(4.2)$ & $.001^{*}$ \\
\hline Motivation to quit (Average, SD) & $6.7(1.7)$ & $6.9(1.5)$ & .23 \\
\hline Fagerström (Mean, DP) & $9.4(2.3)$ & $9.0(2.2)$ & .06 \\
\hline Cigarettes smoked per day (Mean, SD) & $19.7(10.9)$ & $17.2(9.8)$ & $.05^{*}$ \\
\hline AUDIT-C (Mean, SD) & $3.9(2.9)$ & $4.3(3.0)$ & .33 \\
\hline Previous quitting attempts (Mean, SD) & $6.0(7.1)$ & $5.9(7.1)$ & .83 \\
\hline \# of Pages Viewed (Average, SD) & $14.3(9.7)$ & $13.2(9.7)$ & .25 \\
\hline
\end{tabular}

Note: * p-value $<.05$ 
Table 2

Spearman's correlation matrix of sociodemographic variables, nicotine dependence, motivation to quit, alcohol drinking, and use of the intervention by participants $(\mathrm{n}=461)$

\begin{tabular}{|c|c|c|c|c|c|c|c|}
\hline & Age & Motivation & FTND $^{1}$ & $\begin{array}{c}\text { Cigarettes } \\
\text { smoked } \\
\text { per day }\end{array}$ & $\begin{array}{c}\text { \# of pages } \\
\text { viewed }\end{array}$ & AUDIT-C 2 & $\begin{array}{c}\text { Previous } \\
\text { attempts } \\
\text { to quit }\end{array}$ \\
\hline Motivation & $-.13^{* *}$ & & & & & & \\
\hline FTND $^{1}$ & $.15^{\star \star}$ & $-.15^{\star \star}$ & & & & & \\
\hline Cigarettes smoked per day & $.18^{* *}$ & $-.16^{* *}$ & $.67^{\star * *}$ & & & & \\
\hline \# of Pages Viewed & -.02 & .07 & .00 & -.04 & & & \\
\hline AUDIT-C ${ }^{2}$ & $-.17^{*}$ & -.12 & .01 & .11 & -.02 & & \\
\hline Previous Attempts to quit & .03 & .01 & -.02 & .08 & .02 & -.10 & \\
\hline PHQ-93 & -.06 & -.05 & $.20^{* * *}$ & $.13^{*}$ & -.01 & .14 & .14 \\
\hline
\end{tabular}

Note: ${ }^{1}$ Fagerström Test for Nicotine Dependence; ${ }^{2}$ Alcohol Use Disorder Identification Test (AUDIT-C); ${ }^{3}$ Patient Health Questionnaire (PHQ-9); ${ }^{*} p$-value $<.05 ;{ }^{* *} p$-value $<.01 ;{ }^{* * *} p$-value $<.001$.

icant predictors of being screened as depressed. Higher levels of nicotine dependence were associated with depression $(\mathrm{OR}=1.10 ; 95 \% \mathrm{CI}=1.00,1.20)$. While for unemployed people, the risk of having depression was higher $(\mathrm{OR}=.53$, $95 \% \mathrm{CI}=.29, .97)$; that is, an employed person is .53 times less likely of having depression. More complex models (i. e., with variables as: age, gender, nicotine dependence, previous quit attempts) were not statistically significant.

\section{DISCUSSION AND CONCLUSION}

In this study, we evaluated the prevalence of depressive symptoms and found which participants' characteristics were associated with depression. We found that depression affects a considerable proportion of smokers seeking help to quit smoking. Moreover, the results also suggest an association between being unemployed and being diagnosed with depression. There was also a positive weak association between nicotine dependence and depressive symptoms. It was also found a moderate positive correlation between the number of cigarettes smoked per day and nicotine dependence and a weak negative correlation between smoking dependence and participants' motivation. However, we did not find significant correlations for the variables: age, sex, education, motivation to quit, attempts to quit, and the number of pages visited.
The proportion of smokers with depression in webbased interventions for smokers varies between $12.9 \%$ to $40.0 \%$. The percentage we found was similar to the Bricker's study (2013), in which approximately $40 \%$ of the participants were diagnosed with depression. In the study carried out by Rabius et al. (2008), the rate of participants with depression diagnosis was 30\%. However, the values were different from the study by Muñoz et al. (2009), in which $12.9 \%$ of the participants were diagnosed with depression. It is important to note that all studies used different measures for assessing depression. Besides, the prevalence we found was different from the study of Andrade et al. (2012) conducted in a representative sample in Brazil. Andrade found the 12-month prevalence of major depression was $9.4 \%$. Besides, we found that women were screened as depressed in a greater proportion than men even though the result was not statistically significant. Depression is more prevalent in women than men in the general population despite age (Salk, Hyde, \& Abramson, 2017) and have greater impact on smoking cessation treatment (Weinberger, Mazure, Morlett, \& McKee, 2013).

Our results also suggest an association between unemployment and depression, complying with studies that describe unemployment as a risk factor for depression (Wilhelm, Mitchell, Slade, Brownhill, \& Andrews, 2003; Zimmerman \& Katon, 2005). In addition, according to Kessler, Greenberg, Mickelson, Meneades, and Wang

Table 3

Comparison between logistic regression models with imputed data and the complete cases

\begin{tabular}{|c|c|c|c|c|c|c|c|c|}
\hline & \multicolumn{4}{|c|}{ Model with imputed data ${ }^{1}$} & \multicolumn{4}{|c|}{ Model with complete observations } \\
\hline & $B(E P)$ & OR & $95 \% \mathrm{Cl}$ & $95 \% \mathrm{Cl}$ & $B(E P)$ & OR & $95 \% \mathrm{Cl}$ & $95 \% \mathrm{Cl}$ \\
\hline Constant & $\begin{array}{r}-1.04 \\
(.46)\end{array}$ & $.35^{*}$ & .14 & .88 & $\begin{array}{l}-.21 \\
(.62)\end{array}$ & .81 & .24 & 2.72 \\
\hline Tobacco dependence (FTND²) & $\begin{array}{c}.09 \\
(.05)\end{array}$ & $1.10^{*}$ & 1.00 & 1.20 & $\begin{array}{l}-.01 \\
(.07)\end{array}$ & 1.00 & .88 & 1.14 \\
\hline Working [Yes] & $\begin{array}{l}-.63 \\
(.30)\end{array}$ & $.53^{*}$ & .29 & .97 & $\begin{array}{l}-.63 \\
(.30)\end{array}$ & .53 & .30 & .96 \\
\hline
\end{tabular}

Notes: ${ }^{1}$ Model with 55 multiple imputations; ${ }^{2}$ FTND $=$ Fagerstrom Test for Nicotine Dependence; ${ }^{*} p<.05$. 
(2001), depression is one of the leading health conditions to quit work and is related with having a generally good socioeconomic position (van de Velde, Bracke, \& Levecque, 2010). Although these studies have found a correlation between depression and unemployment, it is difficult to establish the causal relationship. Our findings about the positive association between depression and nicotine dependence also have been reported elsewhere (Breslau, 1995; Breslau, Peterson, Schultz, Andreski, \& Chilcoat, 1996).

While studies show that different factors play a role in predicting quitting attempts and their success, especially motivation (Smit, Hoving, Schelleman-Offermans, West, $\&$ de Vries, 2014), the results of our analyses showed no relationship between them. Although participants were motivated to stop smoking, we found no correlation between motivation and previous attempts to quit smoking.

Our study has some limitations. First, we collected information through online self-reported questionnaires. To reduce false responses, user accounts were inspected and potential false users were removed. Second, data collection was performed at different intervention pages, which led to missing data. To address this issue, we used the multiple imputation method to reduce the standard errors and provide more accurate results that need to be verified in further studies. Third, other comorbidities (e. g., anxiety disorders, substance use disorders, and personality disorders) were not assessed. Future studies should address the prevalence of these comorbidities.

In conclusion, depression may be present among Portuguese speakers that seek help to quit smoking online. Future studies should evaluate the impact of depression in the treatment outcomes. Programs available on the internet could also include tailored content to depressive smokers, as well as provide referral to health services. Given the association between depression and smoking, websites offering counseling or crisis management for depression may also refer users to smoking services. Future studies are also needed to identify other comorbidities such as anxiety and personality disorders.

\section{Funding}

CNPq/CAPES-Casadinho/Procad (Processo 552452/2011-4), FAPEMIG - Demanda Universal (N SHA-APQ-01982-11), Pronem (N SHA-APQ-04279-10), CAPES Scholarship\#103897/2012/2013.

\section{Conflict of interests}

The authors declare that they have no conflict of interests.

\section{REFERENCES}

Andrade, L. H., Wang, Y. P., Andreoni, S., Silveira, C. M., Alexandrino-Silva, C., Siu, E. R., ... \& Viana, M. C. (2012). Mental Disorders in Megacities: Findings from the São Paulo Megacity Mental Health Survey, Brazil. PLoS ONE, 7(2), e31879. doi: 10.1371/journal.pone.0031879

Breslau, N. (1995). Psychiatric comorbidity of smoking and nicotine dependence. Behavior Genetics, 25(2), 95-101.
Breslau, N., Peterson, E., Schultz, L., Andreski, P., \& Chilcoat, H. (1996). Are Smokers with Alcohol Disorders Less Likely to Quit? American Journal of Public Health, 86(7), 985-985.

Bricker, J., Wyszynski, C., Comstock, B., \& Heffner, J. L. (2013). Pilot Randomized Controlled Trial of Web-Based Acceptance and Commitment Therapy for Smoking Cessation. Nicotine \& Tobacco Research, 15(10), 1756-1764. doi: $10.1093 / \mathrm{ntr} / \mathrm{ntt} 056$

Buuren, S. van, \& Groothuis-Oudshoorn, K. (2011). Mice: Multivariate Imputation by Chained Equations in R. Journal of Statistical Software, 45(3), 1-67. Retrieved from: http://www.jstatsoft.org/v45/i03/

Cahill, K., Lancaster, T., \& Green, N. (2010). Stage-based interventions for smoking cessation. Cochrane Database of Systematic Reviews. doi: 10.1002/14651858. CD004492.pub4

Civljak, M., Stead, L. F., Hartmann-Boyce, J., Sheikh, A., \& Car, J. (2013). Internet-based interventions for smoking cessation. In Cochrane Database of Systematic Reviews. doi: 10.1002/14651858.CD007078.pub4

Covey, L. S., Glassman, A. H., \& Stetner, F. (1990). Depression and depressive symptoms in smoking cessation. Comprehensive Psychiatry, 31(4), 350-354. doi: 10.1016/0010-440X(90)90042-Q

Croissant, Y. (2013). mlogit: multinomial logit model. Retrieved from: https:// CRAN.R-project.org/package $=$ mlogit

De Meneses-Gaya, C., Zuardi, A. W., Marques, J. M. de A., Souza, R. M., Loureiro, S. R., \& Crippa, J. A. S. (2009). Psychometric qualities of the Brazilian versions of the Fagerström Test for Nicotine Dependence and the Heaviness of Smoking Index. Nicotine \& Tobacco Research, 11(10), 1160-1165. doi: 10.1093/ntr/ntp114

De Meneses-Gaya, C., Zuardi, A. W., Loureiro, S. R., Hallak, J. E. C., Trzesniak, C., De Azevedo Marques, J. M., ... \& Crippa, J. A. S. (2010). Is the full version of the AUDIT really necessary? Study of the validity and internal construct of its abbreviated versions. Alcoholism: Clinical and Experimental Research, 34(8), 1417-1424. doi: 10.1111/j.1530-0277.2010.01225.x

Farrell, M., Howes, S., Bebbington, P., Brugha, T., Jenkins, R., Lewis, G., .. \& M Meltzer, H. (2001). Nicotine, alcohol and drug dependence and psychiatric comorbidity. Results of a national household survey. The British Journal of Psychiatry: The Journal of Mental Science, 179(5), 432-437.

Global Adult Tobacco Survey Collaborative Group. (2010). Global Adult Tobacco Survey (GATS): Core Questionnaire with Optional Questions. Centers for Disease Control and Prevention. Retrieved from: http://www.who.int/tobacco/surveillance/en_tfi_gats_corequestionnairewithoptionalquestions_v2_FINAL_03Nov2010.pdf?ua $=1$

Gomide, H. P., Bernardino, H. S., Richter, K., Martins, L. F., \& Ronzani, T. M. (2016). Development of an open-source web-based intervention for Brazilian smokers-Viva sem Tabaco. BMC Medical Informatics and Decision Making, 16(1), 103. doi:10.1186/s12911-016-0339-7

Hartmann-Boyce, J., Stead, L. F., Cahill, K., \& Lancaster, T. (2013). Efficacy of interventions to combat tobacco addiction: Cochrane update of 2012 reviews. Addiction, 108(10), 1711-1721. doi: 10.1111/add.12291

Heatherton, T. F., Kozlowski, L. T., Frecker, R. C., \& Fagerstrom, K.-O. (1991). The Fagerstrom Test for Nicotine Dependence: a revision of the Fagerstrom Tolerance Questionnaire. British Journal of Addiction, 86(9), 1119-1127.

Hitsman, B., Borrelli, B., McChargue, D. E., Spring, B., \& Niaura, R. (2003). History of depression and smoking cessation outcome: a meta-analysis. Journal of Consulting and Clinical Psychology, 71(4), 657-663.

Husky, M. M., Mazure, C. M., Paliwal, P., \& McKee, S. A. (2008). Gender differences in the comorbidity of smoking behavior and major depression. Drug and alcohol dependence, 93(1-2), 176-179. doi: 10.1016/j.drugalcdep.2007.07.015

Kendler, K. S., Neale, M. C., MacLean, C. J., Heath, A. C., Eaves, L. J., \& Kessler, R. C. (1993). Smoking and major depression. A causal analysis. Archives of General Psychiatry, 50(1), 36-43.

Kessler, R. C., Greenberg, P. E., Mickelson, K. D., Meneades, L. M., \& Wang, P. S. (2001). The effects of chronic medical conditions on work loss and work cutback. Journal of Occupational and Environmental Medicine, 43(3), 218-225.

Manea, L., Gilbody, S., \& McMillan, D. (2015). A diagnostic meta-analysis of the Patient Health Questionnaire-9 (PHQ-9) algorithm scoring method as a screen for depression. General Hospital Psychiatry, 37(1), 67-75. doi: 10.1016/j.genhosppsych.2014.09.009 
McClave, A. K., Dube, S. R., Strine, T. W., Kroenke, K., Caraballo, R. S., \& Mokdad, A. H. (2009). Associations between smoking cessation and anxiety and depression among U.S. adults. Addictive Behaviors, 34(6-7), 491-497. doi: 10.1016/j. addbeh.2009.01.005

Morozova, M., Rabin, R. A., \& George, T. P. (2015). Co-morbid tobacco use disorder and depression: A re-evaluation of smoking cessation therapy in depressed smokers: Smoking cessation in depression. The American Journal on Addictions, 24(8), 687-694. doi: 10.1111/ajad.12277

Muñoz, R., Barrera, A. Z., Delucchi, K., Penilla, C., Torres, L. D., \& Pérez-Stable, E. J. (2009). International Spanish/English Internet smoking cessation trial yields 20\% abstinence rates at 1 year. Nicotine \& Tobacco Research, 11(9), 1025-1034. doi: $10.1093 /$ ntr/ntp090

Muñoz, R. F. (2010). Using Evidence-Based Internet Interventions to Reduce Health Disparities Worldwide. Journal of Medical Internet Research, 12(5), e60. doi: 10.2196/jmir. 1463

Pettersson, A., Boström, K. B., Gustavsson, P., \& Ekselius, L. (2015). Which instruments to support diagnosis of depression have sufficient accuracy? A systematic review. Nordic Journal of Psychiatry, 69(7), 497-508. doi: 10.3109/08039488.2015.1008568

Rabius, V., Pike, K. J., Wiatrek, D., \& McAlister, A. L. (2008). Comparing Internet Assistance for Smoking Cessation: 13-Month Follow-Up of a Six-Arm Randomized Controlled Trial. Journal of Medical Internet Research, 10(5), e45. doi: 10.2196/jmir.1008

R Core Team. (2017). R: A Language and Environment for Statistical Computing. Vienna, Austria: R Foundation for Statistical Computing. Retrieved from: https:// www.R-project.org/

Reid, H. H., \& Ledgerwood, D. M. (2016). Depressive symptoms affect changes in nicotine withdrawal and smoking urges throughout smoking cessation treatment: Preliminary results. Addiction Research \& Theory, 24(1), 48-53. doi: 10.3109/16066359.2015.1060967

Rubin, D. B. (1987). Multiple imputation for nonresponse in surveys. New York: John Wiley \& Sons.

Salk, R. H., Hyde, J. S., \& Abramson, L. Y. (2017). Gender differences in depression in representative national samples: Meta-analyses of diagnoses and symptoms. Psychological Bulletin, 143(8), 783-822. doi: 10.1037/bul0000102

Santos, I. S., Tavares, B. F., Munhoz, T. N., Almeida, L. S. P., Silva, N. T. B., Tams, B. D., ... \& Matijasevich, A. (2013). Sensitivity and specificity of the Patient Health Questionnaire-9 (PHQ-9) among adults from the general population. Cadernos de Saúde Pública, 29(8), 1533-1543. doi: 10.1590/0102-311X00144612
Smit, E. S., Hoving, C., Schelleman-Offermans, K., West, R., \& de Vries, H. (2014). Predictors of successful and unsuccessful quit attempts among smokers motivated to quit. Addictive behaviors, 39(9), 1318-1324. doi: 10.1016/j.addbeh.2014.04.017

Taylor, G., McNeill, A., Girling, A., Farley, A., Lindson-Hawley, N., \& Aveyard, P. (2014). Change in mental health after smoking cessation: systematic review and meta-analysis. BMJ, 348(1), g1151-g1151. doi: 10.1136/bmj.g1151

Terra, M. B., Silveira, D. X., Moreira, T. de C., Ferigolo, M., Mazoni, C., Arena, F. X., \& Barros, H. M. T. (2009). Convergent validation study of the Contemplation Ladder for application via telephone in tobacco users. Jornal Brasileiro de Psiquiatria, 58(3), 143-149. doi: 10.1590/S0047-20852009000300001

US Department of Health and Human Services. (2008). Treating Tobacco Use and Dependence: 2008 Update.

Van der Meer, R. M., Willemsen, M. C., Smit, F., \& Cuijpers, P. (2013). Smoking cessation interventions for smokers with current or past depression. Cochrane Database of Systematic Reviews. doi: 10.1002/14651858.CD006102.pub2

Van de Velde, S., Bracke, P., \& Levecque, K. (2010). Gender differences in depression in 23 European countries. Cross-national variation in the gender gap in depression. Social Science \& Medicine, 71(2), 305-313. doi: 10.1016/j. socscimed.2010.03.035

Weinberger, A. H., Mazure, C. M., Morlett, A., \& McKee, S. A. (2013). Two decades of smoking cessation treatment research on smokers with depression: 19902010. Nicotine \& Tobacco Research , 15(6), 1014-1031. doi: 10.1093/ntr/nts213

Wilhelm, K., Mitchell, P., Slade, T., Brownhill, S., \& Andrews, G. (2003). Prevalence and correlates of DSM-IV major depression in an Australian national survey. Journal of Affective Disorders, 75(2), 155-162. doi: 10.1016/S01650327(02)00040-X

World Health Organization. (2008). WHO Report on the Global Tobacco Epidemic: The MPOWER package. Geneva: World Health Organization.

Zimmerman, F. J., \& Katon, W. (2005). Socioeconomic status, depression disparities, and financial strain: what lies behind the income-depression relationship? Health Economics, 14(12), 1197-1215. doi: 10.1002/hec.1011

Zvolensky, M. J., Bakhshaie, J., Sheffer, C., Perez, A., \& Goodwin, R. D. (2015). Major depressive disorder and smoking relapse among adults in the United States: A 10-year, prospective investigation. Psychiatry Research, 226(1), 73-77. doi: 10.1016/j.psychres.2014.11.064 